\title{
Effects of Mechanically Activated Milling and Calcination Process on the Phase Stability and Particle Morphology of Monoclinic Zirconia Synthesized by Hydrolysis of $\mathrm{ZrOCl}_{2}$ Solution
}

\author{
Young-Geun Lee, Soon-Chul Ur, Iqbal Mahmud and Man-Soon Yoon ${ }^{\dagger}$ \\ Department of Materials Science and Engineering / RIC-ReSEM, Korea National University of Transportation, \\ Daehakno, Chungju, Chungbuk 380-702, Korea
}

(Received June 13, 2013 : Received in revised form July 18, 2013 : Accepted July 19, 2013)

\begin{abstract}
The purpose of this paper was to investigate the effect of a high-energy milling (HEM) process on the particle morphology and the correlation between a thermal treatment and tetragonal/monoclinic nanostructured zirconia powders obtained by a precipitation process. To eliminate chloride residue ions from hydrous zirconia, a modified washing method was used. It was found that the used washing method was effective in removing the chloride from the precipitated gel. In order to investigate the effect of a pre-milling process on the particle morphology of the precipitate, $\operatorname{dried~} \mathrm{Zr}(\mathrm{OH})_{4}$ was milled using a HEM machine with distilled water. The particle size of the $\mathrm{Zr}(\mathrm{OH})_{4}$ powder exposed to HEM reduced to $100 \sim 150 \mathrm{~nm}$, whereas that of fresh $\mathrm{Zr}(\mathrm{OH})_{4}$ powder without a pre-milling process had a large and irregular size of $100 \mathrm{~nm} \sim 1.5 \mu \mathrm{m}$. Additionally, modified heat treatment process was proposed to achieve nano-sized zirconia having a pure monoclinic phase. It was evident that two-step calcining process was effective in perfectly eliminating the tetragonal phase, having a small average particle of $\sim 100 \mathrm{~nm}$ with good uniformity compared to the sample calcined by a single-step process, showing a large average particle size of $\sim 300 \mathrm{~nm}$ with an irregular particle shape and a broad particle size distribution. The modified method is considered to be a promising process for nano-sized zirconia having a fully monoclinic phase.
\end{abstract}

Key words high energy milling, SEM, XRD, calcination.

\section{Introduction}

Zirconia $\left(\mathrm{ZrO}_{2}\right)$ has found widespread applications due to its unique physical and chemical properties. It has been used as a structural material because of its high strength, toughness, high chemical resistance, and thermal stability. Compared to other ceramic metal oxides, zirconia possesses much better alkali resistance, showing an outstanding resistance to dissolution at a high temperature. ${ }^{1)}$ Because of these favorable properties and the presence of acid-base or oxidation reduction centers, zirconia has been used in catalytic applications as a support or an active phase. ${ }^{2-4)}$ Recent studies have shown that the use of nanostructured zirconia instead of conventional micrometersized zirconia enhances efficiency in many applications. ${ }^{5)}$ Monoclinic phase zirconia is widely used for construction ceramics including refractory and insulation materials, medical use and the electrolyte in solid oxide fuel cell (SOFC). Moreover it is an important component of leadzirconia-titanate(PZT) piezoelectric ceramics. Monoclinic phase zirconia can be used as an additive to enhance the properties of other oxide refractories, setter sands, thermal coatings, and as separation media. These products are also used in other applications that require an inert material, high melting point, and low thermal conductivity. It is particularly advantageous when added to high-fired magnesia and alumina bodies. It promotes sinterability and with alumina, contributes to abrasive characteristics. Pure ultrafine /nanoscale monoclinic phase of zirconia has advantages in producing excellent PZT ceramics. Fine powder of monoclinic phase zirconium oxide is very important starting material for the manufacturing of various dielectric, piezoelectric ceramics. Zirconia exists in three polymorphic modifications: monoclinic, tetragonal, and cubic, with in-

\footnotetext{
${ }^{\dagger}$ Corresponding author

E-Mail : msyoon@ut.ac.kr (M.-S. Yoon, Korea Nat'l Univ.)
}

(C) Materials Research Society of Korea, All rights reserved.

This is an Open-Access article distributed under the terms of the Creative Commons Attribution Non-Commercial License (http://creativecommons.org/licenses/by-nc/3.0) which permits unrestricted non-commercial use, distribution, and reproduction in any medium, provided the original work is properly cited. 
creasing temperature. Although the monoclinic form is stable at room temperature at a low surface area, ${ }^{6,7)}$ nanocrystalline zirconia synthesized at room temperature is tetragonal. ${ }^{8)}$ In bulk, the tetragonal phase is stable only above $1170{ }^{\circ} \mathrm{C}$ and transforms into the cubic phase near $2370{ }^{\circ} \mathrm{C}$. This stabilization of the tetragonal phase in the nanocrystalline regime is attributed to the difference in the surface energies of monoclinic and tetragonal phases, the latter being smaller. ${ }^{9-11)}$ Therefore, it is difficult to synthesis the fully stabilized monoclinic phase in nanosized $\mathrm{ZrO}_{2}$. In order to prepare $\mathrm{ZrO}_{2}$ nanocrystalline powder, several methods have been used. Among them, precipitation route ${ }^{12-13)}$ is relatively simple and easy scaleup process with low energy consumption, comparison to other various wet chemistry processes such as hydrothermal ${ }^{14-18)}$ processing, sol-gel processing, ${ }^{19)}$ and so forth. Furthermore, chloride residue is known to retard $\mathrm{ZrO}_{2}$ densification in this process. ${ }^{20)}$

The main purpose of this paper is to synthesize a nanosized monoclinic zirconia powders with regular particle shape and to correlate phase stability with calcination condition. For these purpose, the monoclinic $\mathrm{ZrO}_{2}$ are fabricated by precipitation process.

\section{Experimental Procedure}

Aqueous solution with $\mathrm{Zr}^{+4}$ concentration of $0.1 \mathrm{M}$ was prepared using $\mathrm{ZrOCl}_{2}-8 \mathrm{H}_{2} \mathrm{O}$ (99.0\% purity: Zhejiang Shenghua Biok Biology Co., Ltd, China) as a starting material. A solution of $1 \mathrm{M}$ ammonia was then slowly added to the solution to control $\mathrm{pH}$ value with vigorous stirring at room temperature until $\mathrm{pH}$ reached 11 . This alkaline solution was continuously stirred for $1 \mathrm{~h}$ and aged for $24 \mathrm{~h}$ until a gel like precipitate appeared, which was washed several times with distilled water. The washed precipitate was subsequently washed again with $8 \%$ ammonia solution for complete removal of $\mathrm{Cl}^{-}$ions. The two step washed precipitate was washed several times with distilled hot water of $80{ }^{\circ} \mathrm{C}$. After final washing process, the removal of $\mathrm{Cl}^{-}$ions was verified by means of $3 \mathrm{M}$ $\mathrm{AgNO}_{3}$ solution titration. The precipitate gel was then dehydrated with absolute EtOH and isopropyl alcohol (IPA). The dehydrated gel was converted into slurry with distilled water. The slurry was milled to enhance the reaction kinetics and ensure the particle uniformity during the calcination step using a high energy milling machine (MINICER/MINIPUR-NETZSCH). Milling process was conducted with zirconia balls of $0.1 \mathrm{~mm}$ diameter for $1 \mathrm{~h}$ with rotor speed of $3500 \mathrm{rpm}$. The powder was then heat treated in air at $400{ }^{\circ} \mathrm{C} \sim 1000{ }^{\circ} \mathrm{C}$ for $4 \mathrm{~h}$ to obtain crystalline $\mathrm{ZrO}_{2}$ powder. After calcining, an additional milling step using HEM was conducted to obtain a nano-particle size. The powder morphologies of the all samples were investigated using a scanning electron microscope(SEM; FEI Company Quanta 400). The chemical composition of the powder was determined by X-ray fluorescence spectroscopy(SHIMADZU, ED-XRF 720). The volume fraction of monoclinic phase, $V_{m}$, was evaluated by the Toraya method. $^{21)}$

$$
\begin{aligned}
& V_{m}=1.311 X_{m} /\left(1+0.311 X_{m}\right) \\
& X_{m}=\left\{I_{(-111) m}+I_{(111) m}\right\} /\left\{I_{(11) t}+I_{(-111) m}+I_{(111) m}\right\}
\end{aligned}
$$

Where $X_{m}$ is the integrated intensity ration and the subscripts $m$ and $t$ of $I$ represent the peak intensities of $\mathrm{K \alpha}_{1}$ for monoclinic and tetragonal phases, respectively, after peak separation and fitting. The average crystallite size $\left(d_{X R D}\right)$ of the monoclinic phase was estimated according to the Scherrer equation. ${ }^{22)}$

$$
\mathrm{d}_{\mathrm{XRD}}=0.94 \lambda / \beta \cos \theta
$$

Where, $\theta$ is the diffraction angle of the (111) peak, $\beta$ is the full width at half-maximum(FWHM) of the (111) peak. The Brenauer-Emmett-Teller(BET) surface area was measured by nitrogen physisorption at $76.5 \mathrm{~K}$ using an ASAP 2020 analyzer(Micromeritics Co. Ltd., Norcross, GA).

\section{Results and Discussion}

\subsection{Effect of washing method on chlorine removal}

The chemical compositions of the powder as determined by X-ray fluorescence spectroscopy(XRF) was shown in Table 1. According to these results, residual $\mathrm{Cl}^{-}$ions was not observed. The removal of $\mathrm{Cl}^{-}$ions is very important step because residual chlorine greatly interferes with the sintering of zirconia powders at low temperatures. ${ }^{20)}$ In general, ammonia water induced the chloride removal with a simple reaction $\left(\mathrm{Cl}^{-}+\mathrm{NH}_{3(\mathrm{aq})} \rightarrow \mathrm{NH}_{4} \mathrm{Cl}_{(\mathrm{aq})}\right)$. In addition to this reaction, the precipitate was subsequently washed with distilled hot water $\left(80^{\circ} \mathrm{C}\right)$. It is well known that solubility of $\mathrm{NH}_{4} \mathrm{Cl}$ is much higher at hot water rather than cold/normal temperature water. Therefore, higher solubility of $\mathrm{NH}_{4} \mathrm{Cl}$ in hot water enhanced the chloride removal from the precipitated gel during filtration process. Thus, it could be predicted that the used washing method was effective in removing the chloride ions of precipitated

Table 1. Analyzed XRF data for the precipitated gel.

\begin{tabular}{ccc}
\hline Analyte & Result(\%) & Int.(cps/ $\mu \mathrm{A})$ \\
\hline $\mathrm{Zr}$ & 73.06 & 2564.2653 \\
$\mathrm{P}$ & 23.778 & 2.6796 \\
$\mathrm{Si}$ & 2.074 & 0.1138 \\
$\mathrm{Hf}$ & 1.087 & 15.3542 \\
\hline
\end{tabular}


gel. Furthermore, ethanol washing step decreased the agglomeration of precipitates.

\subsection{Thermal analysis and crystal structure of pre- cipitate}

The DSC curve of hydrous-zirconia particles obtained from precipitation is shown in Fig. 1. The first endothermic peak is appeared at $137{ }^{\circ} \mathrm{C}$ followed by a second endothermic peak at $360^{\circ} \mathrm{C}$. The first endothermic peak corresponds to the elimination of residual water and solvent, the second endothermic peak is due to the decomposition of $\mathrm{Zr}(\mathrm{OH})_{4}$ into amorphous $\mathrm{ZrO}_{2}$. The exothermic peak appeared at $475^{\circ} \mathrm{C}$, indicating the crystallization of amorphous $\mathrm{ZrO}_{2}$ to crystal structure. An X-ray diffraction pattern for the precipitate dried at $75^{\circ} \mathrm{C}$ is shown in Fig. 2. The broad band, in the range of $2 \theta \sim 30^{\circ}$, indicates an essentially amorphous precipitate with some nearestneighbor ordering.

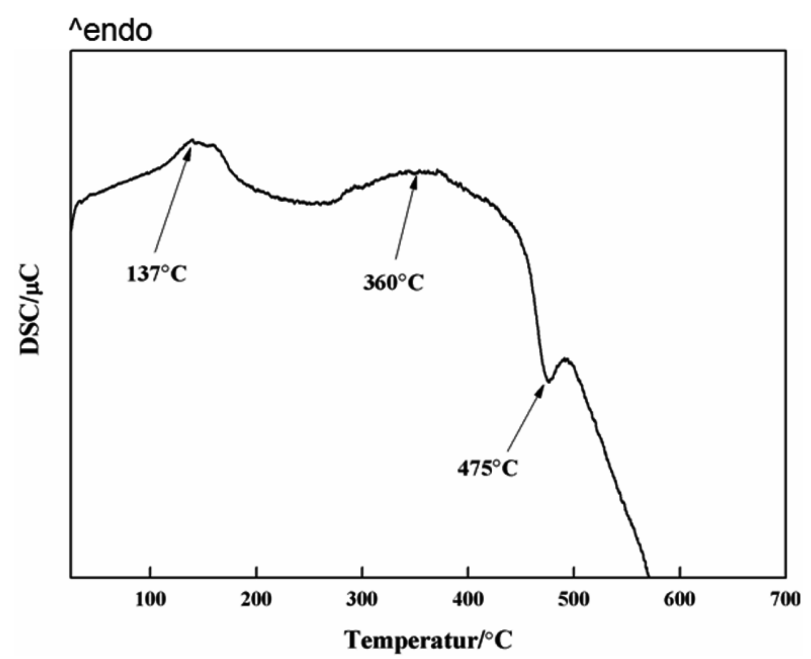

Fig. 1. The DSC profile of the $\mathrm{Zr}(\mathrm{OH})_{4}$ prepared with precipitation technique.

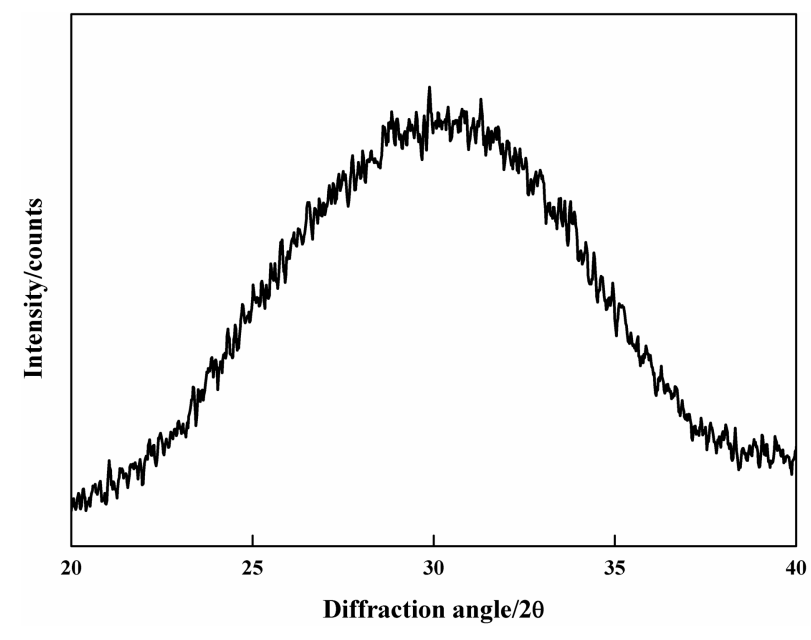

Fig. 2. X-ray diffraction pattern of $\mathrm{Zr}(\mathrm{OH})_{4}$ dried at $75^{\circ} \mathrm{C}$.

\subsection{Effect of pre-milling process on particle mor- phology of the precipitate}

Before calcining, the gels were converted to slurry and mechanically milled by high energy milling machine to ensure fine and uniform particle size. Fig. 3 shows the SEM micrographs of fresh and pre-milled precipitate powder. From the micrograph results of the pre-milled powders, it is evident that the process causes a significant change in powder morphology, accompanying the powder shape change from an irregular shape to a uniform shape. The particle morphology of the powder exposed to high energy milling promoted particle uniformity without agglomeration.

\subsection{Effect of heat treatment}

The data obtained from X-ray diffraction of the calcined powders as a function of heat treatment temperature are shown in Fig. 4. The result indicates that the $\mathrm{Zr}(\mathrm{OH})_{4}$ crystallize into tetragonal phase at $400{ }^{\circ} \mathrm{C}$, showing (111) peak at $2 \theta=30^{\circ}$ (Fig. 4). Zirconia exists in three poly-
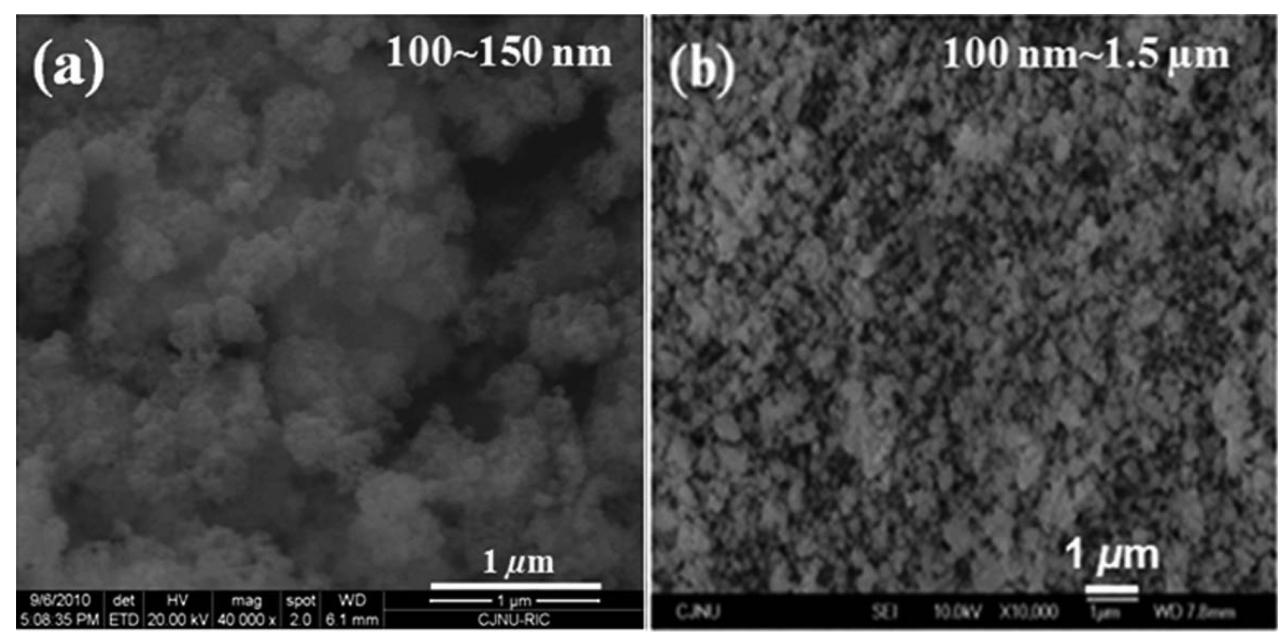

Fig. 3. Scanning electron micrograph of (a) high energy milled (b) fresh $\mathrm{Zr}(\mathrm{OH})_{4}$. 


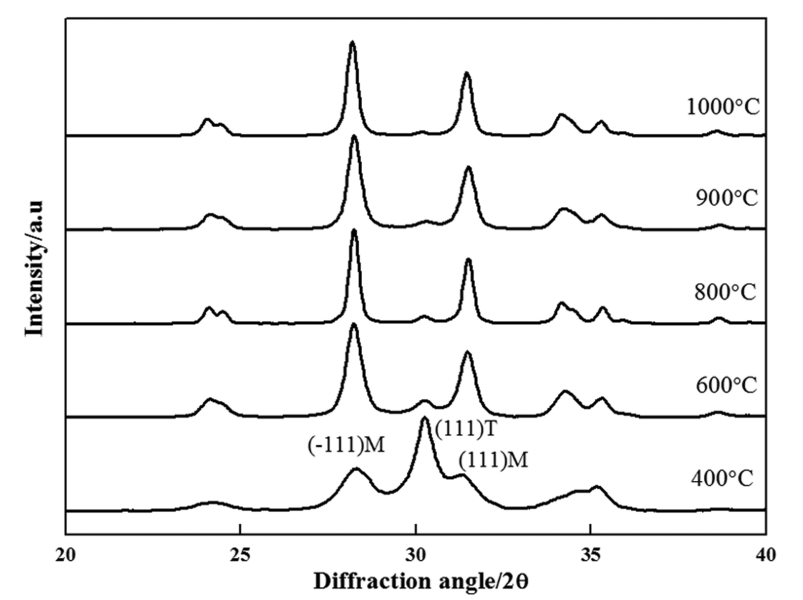

Fig. 4. X-ray diffraction patterns of $\mathrm{ZrO}_{2}$ calcined between $400{ }^{\circ} \mathrm{C}$ and $1000{ }^{\circ} \mathrm{C}$ for $4 \mathrm{~h}$, (T) tetragonal (M) monoclinic phase.

morphic modification; monoclinic, tetragonal and cubic with increasing temperature. While the monoclinic phase is stable at room temperature, nanocrystaline zirconia is stabilized in tetragonal phase at room temperature. ${ }^{8)}$ A model was proposed for explaining the stabilization of the tetragonal phase. According to this model, $\mathrm{OH}^{-}$ions and $\mathrm{Zr}$ vacancies in the crystalline structure play a role of tetragonal phase stabilizers. The model also explained the irreversible phase transformation of the tetragonal to monoclinic phase, which was observed in annealed samples. ${ }^{8)}$ The tetragonal phase is stable even at $400{ }^{\circ} \mathrm{C}$ because of the reduction of the surface energy, which is caused by nano-sized crystallites. After annealing the amorphous $\mathrm{Zr}(\mathrm{OH})_{4}$ at $400{ }^{\circ} \mathrm{C}$, it shows the coexistence of tetragonal and monoclinic phase. ${ }^{9,10)}$ It can be noted that three different lines respectively assigned to the most intense (111) line of the tetragonal phase at $2 \theta=30^{\circ}$ and the $(-111)$ and (111) lines of the monoclinic phase at $2 \theta=28$ and $31.46^{\circ}$. On further increasing of annealing temperature to $600{ }^{\circ} \mathrm{C}$, the increasing of the monoclinic phase takes place, lowering the content of tetragonal phase. This is probably caused by the increase of crystal size as a function of temperature in accordance with the Garvie theory. ${ }^{8)}$ As increasing the annealing temperature
Table 2. Volume fraction of monoclinic phase.

\begin{tabular}{cc}
\hline Annealing temperature $/{ }^{\circ} \mathrm{C}$ & Monoclinic phase $\%$ \\
\hline 400 & 52.24 \\
600 & 92.56 \\
800 & 96.75 \\
900 & 96.86 \\
1000 & 97.03 \\
\hline
\end{tabular}

up to $1000{ }^{\circ} \mathrm{C}$, tetragonal phase tends to decrease and monoclinic phase increases as shown in Fig. 4. This is also evident from the calculated volume fraction of monoclinic phase. Even though calcining temperature increased to $1000{ }^{\circ} \mathrm{C}$, the tetragonal phase of $3 \%$ existed with monoclinic phase as shown in Table 2. Existence of tetragonal phase can be explained by the crystallite size effect. Typical micrographs of the calcined powder obtained in a scanning electron microscope are shown in Fig. 5. The sample calcined at $800{ }^{\circ} \mathrm{C}$ has a smaller average particle size and a more weakened neck growth compared with those of the samples calcined at $900{ }^{\circ} \mathrm{C}$ and $1000{ }^{\circ} \mathrm{C}$, respectively. Based on the analysis above, $\mathrm{Zr}(\mathrm{OH})_{4}$ is decided to calcined at low temperature to obtain the nano size particles, whereas it should be calcined at elevated temperature to increase the monoclinic phase.

3.5 Effect of two step calcination process on the stability of monoclinic phase and powder morphology

As can be seen from the previous sub-section, the stability of monoclinic phase depends on the annealing temperature. Furthermore, the prolonged calcination time can increase the neck growth hindering the effective milling. Therefore, it could be concluded that the increased calcinations time is ineffective in eliminating the tetragonal phase and obtaining the fine particle. In order to achieve a nano-sized zirconia having a pure monoclinic phase, two step calcination process was proposed in this work. Schematic representation of the temperature profile for single and two step calcination is shown in Fig. $6(a-b)$. For two step calcination process, firstly, powders were heated at $850^{\circ} \mathrm{C}$ with the heating rate of $5{ }^{\circ} \mathrm{C} / \mathrm{min}$
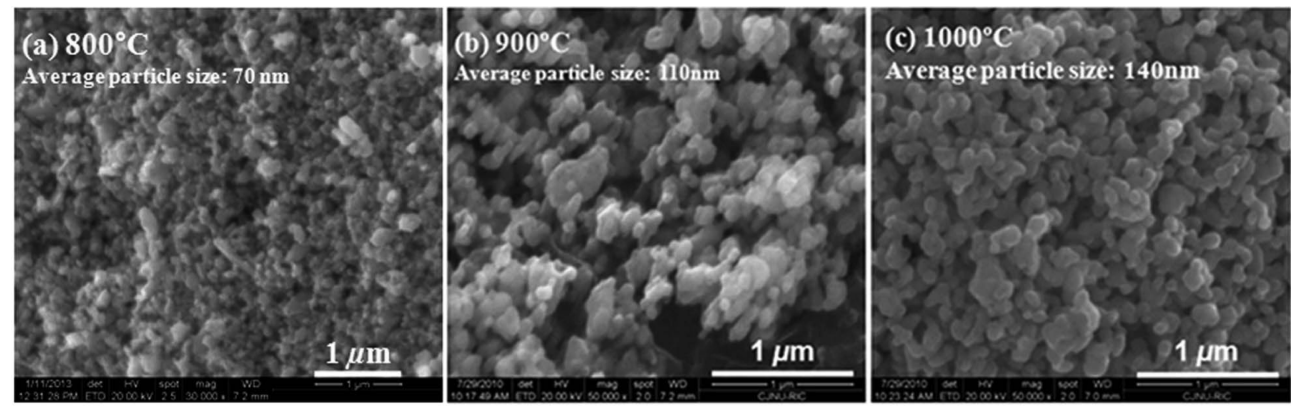

Fig. 5. Scanning electron micrographs of the powders calcined at (a) $800{ }^{\circ} \mathrm{C}$, (b) $900{ }^{\circ} \mathrm{C}$, (c) $1000{ }^{\circ} \mathrm{C}$. 


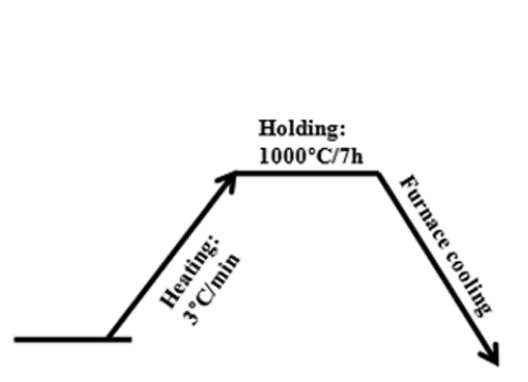

(a) Single step process

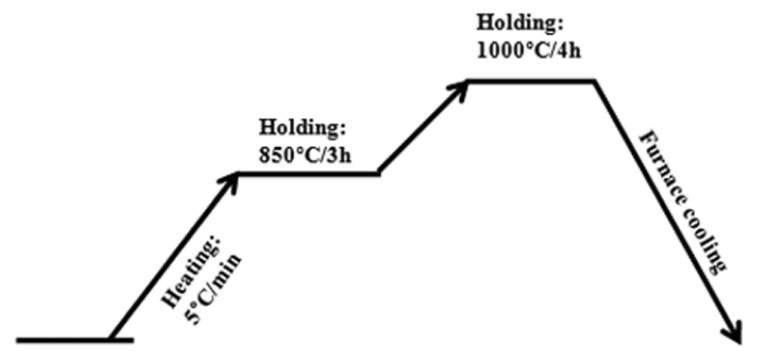

(b)Two step process

Fig. 6. Schematic profile of calcinations process (a) single step and (b) two step method.
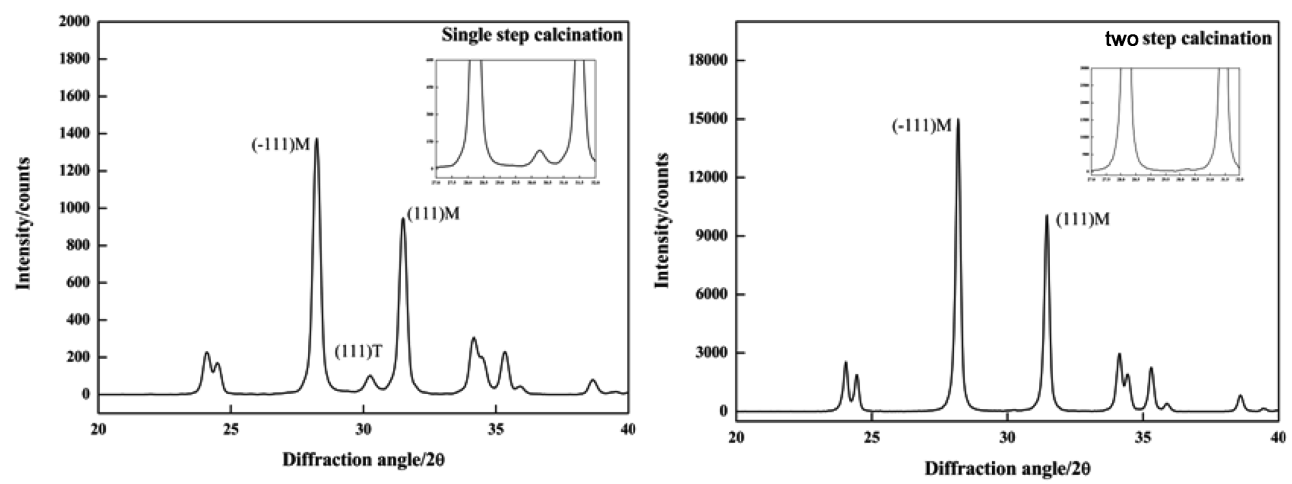

Fig. 7. X-ray diffraction patterns of monoclinic $\mathrm{ZrO}_{2}$ powders calcined by (a) single step and (b) two step process.

and maintained for $3 \mathrm{~h}$ in air atmosphere. Secondly, the temperature was elevated to $1000{ }^{\circ} \mathrm{C}$ with the heating rate of $3{ }^{\circ} \mathrm{C} / \mathrm{min}$ and kept at this temperature for $4 \mathrm{~h}$ and the sample was then cooled down to room temperature.

For the two step calcined powder, the tetragonal (111) peak completely diminished, whereas tetragonal (111) peak still existed for the single step calcined powder in the $2 \theta$ range of $20-40^{\circ}$ and $27-32^{\circ}$ (Fig. 7). To compare the effect of two step calcining process with that of the single step annealing process, another powder sample was prepared at $1000{ }^{\circ} \mathrm{C}$ for $7 \mathrm{~h}$ Fig. $6(\mathrm{a})$. The X-ray diffraction patterns for the two differently calcined powders were shown in Fig. 7. From the X-ray data, volume fraction of monoclinic phase was again calculated using the equation (1) and (2) depicted in Table 3. It is clear that two step calcining process is more effective than the increase of calcinations time in perfectly eliminating the tetragonal phase.

In addition to this, Fig. 8 shows the SEM micrograph of calcined powders fabricated by single step and two step process. The powder fabricated by two step process

Table 3. Monoclinic phase transition with calcination condition.

\begin{tabular}{cc}
\hline Calcination & Monoclinic phase $\%$ \\
\hline Single step & 97.03 \\
Two step & 100.00
\end{tabular}

has a smaller particle size and weaker neck growth than those of the powder fabricated by single step process. A comparison of the result of Fig. 8 with that of Table 3 indicates that the proposed process is effective in eliminating the tetragonal phase and decreasing the particle size compared with single step process. According to previous model, ${ }^{8)} \mathrm{OH}^{-}$ions and $\mathrm{Zr}$ vacancies in the crystalline structure can restrict the stabilization of monoclinic phase. In order to eliminate the defects such as $\mathrm{OH}^{-}$ions, $\mathrm{Zr}$ vacancies and limit the grain growth, an annealing process was chosen during the heat treatment. Regarding the hydroxyl ions $\left[\mathrm{OH}^{-}\right.$ions $]$effects, Vivekanandan and Kutty $^{23)}$ explained the source of lattice strain as from point defects caused by the presence of hydroxyl ions in the oxygen sub-lattice are compensated by cation vacancies, and result in strain leading to the presence of tetragonal phase. Thus, the annealing step at $850{ }^{\circ} \mathrm{C} / 3 \mathrm{~h}$ can remove the defects and reduce the strain with an accompanying the stabilization of the monoclinic phase, thereby reducing the final calcination temperature and sustaining time in order to obtain the ultrafine and fully monoclinic stabilized $\mathrm{ZrO}_{2}$. Furthermore, it takes less processing time than single step process. Therefore, it is expected that the two step calcinations method enhances the monoclinic stabilization due to the increase of crystallite size, and decreases the particle size, weakens neck growth. 

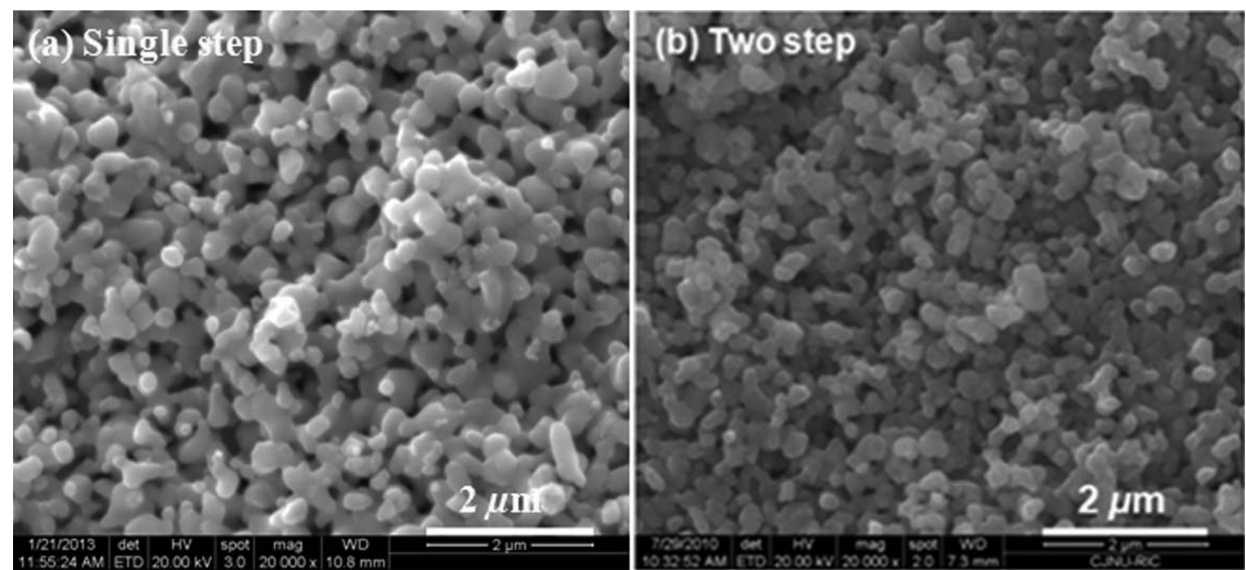

Fig. 8. The SEM morphology of calcined powder fabricated by (a) single step process, (b) two step process.
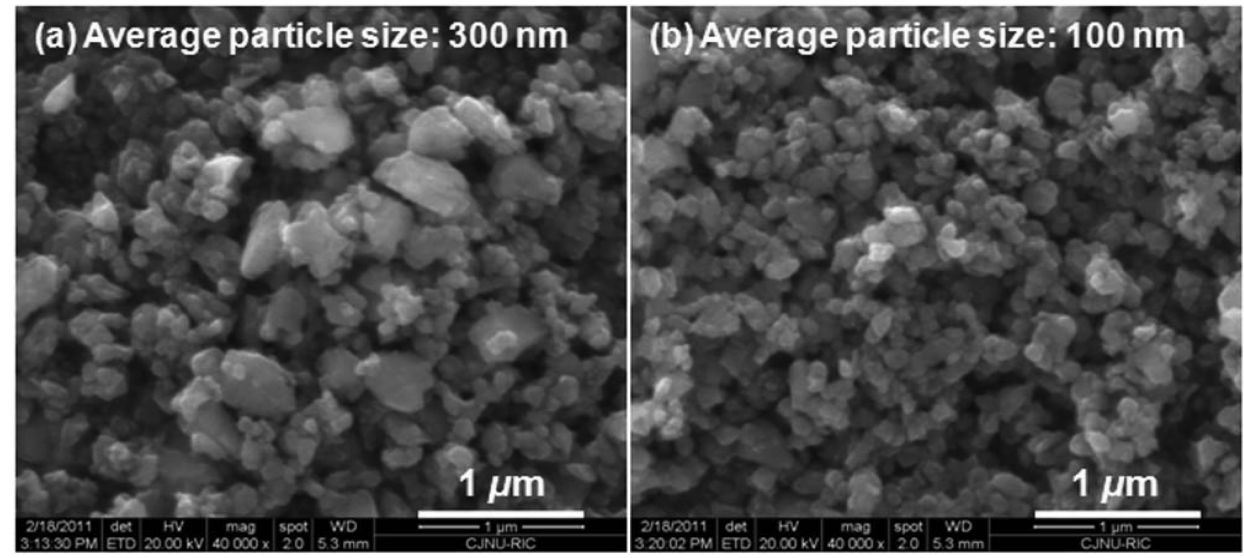

Fig. 9. The SEM morphology of high energy-milled powders calcined by (a) single step process, (b) two step process.

To obtain fine particle, the powders were mechanically milled with nano-mill under the same milling condition. Fig. 9(a) and (b) show the SEM morphologies of the nano-milled powders calcined by single step and two step process, respectively. It indicates that two step calcined powder was more easily and homogenously grinded by milling process due to the weakened neck growth. As shown in Fig. 9 and Table 4, the sample calcined by the two step process has a small average particle of $\sim 100$ $\mathrm{nm}$ (BET surface area: $24.6256 \mathrm{~m}^{2} / \mathrm{g}$ ) with a uniform particle shape. On the other hand, the sample calcined by the single step process has a large average particle of

Table 4. Comparison of crystallite size(measured using the Scherrer equation from XRD) and particle size(measured using the SEM) of the nano-milled powder.

\begin{tabular}{cccc}
\hline Calcination & $\begin{array}{c}\text { Particle } \\
\text { size }(\mathrm{nm}) \\
\text { (From SEM) }\end{array}$ & $\begin{array}{c}\text { BET surface } \\
\text { area }\left(\mathrm{m}^{2} / \mathrm{g}\right)\end{array}$ & $\begin{array}{c}\text { Crystallite } \\
\text { size }(\mathrm{nm}) \\
\text { (From XRD) }\end{array}$ \\
\hline Single step & 300 & 17.0620 & 29.13 \\
Two step & 100 & 24.6256 & 43.09 \\
\hline
\end{tabular}

$\sim 300 \mathrm{~nm}$ (BET surface area: $17.0620 \mathrm{~m}^{2} / \mathrm{g}$ ) with an irregular particle shape and broad particle size distribution compared to the former process. In addition to this, the crystallite size measurements also showed that the double step calcined sample crystallite size is greater than Garvie limit. According to the proposed "crystal size theory" by Garvie, the microcrystals below a critical size of about $30 \mathrm{~nm}$ are stabilized against the tetragonal to monoclinic $(\mathrm{t} \rightarrow \mathrm{m})$ transformation. ${ }^{24)}$ Crystallite size of single step calcined powder is $29.15 \mathrm{~nm}$ which is around the Garvie limit; whereas crystallite size of two steps calcined powder is $43.14 \mathrm{~nm}$, which is over the Garvie limit. Thus, two step calcinations can be stabilized in fully monoclinic phase powders. From the results, it is evident that the two step calcination process is more effective to fabricate the nano-sized and uniform-shaped zirconia powder with fully monoclinic stabilized structure and crystallite size is not significantly affected by the milling process.

\section{Conclusion}

The effects of mechanically activated milling and calci- 
nations process on the phase stability and particle morphology of zirconia produced by hydrolysis of $\mathrm{ZrOCl}_{2}$ were systemically investigated. It was proven that the used washing method was more effective in perfectly removing the chloride ions of precipitated gel from the results of XRF. The effect of pre-milling process on particle morphology of the precipitate was examined using the dried $\mathrm{Zr}(\mathrm{OH})_{4}$. The particle size of the $\mathrm{Zr}(\mathrm{OH})_{4}$ powder exposed to high energy milling reduced to $100 \sim 150 \mathrm{~nm}$, whereas that of fresh $\mathrm{Zr}(\mathrm{OH})_{4}$ powder without premilling process had a large and irregular size of $100 \mathrm{~nm}$ $\sim 1.5 \mu \mathrm{m}$. Additionally, it is clear that the two step calcination process is more effective to fabricate the nanosized and uniform-shaped zirconia powder with pure monoclinic phase showing a small average particle of $\sim 100 \mathrm{~nm}$ with a uniform particle shape compared to the sample calcined by the single step process.

\section{Acknowledgements}

The research was supported by a grant from the Academic Research Program of Korea National University of Transportation in 2013.

\section{References}

1. J. Nawrocki, M. P. Rigney, A. McCormick and P. W. Carr, J. Chromatogr. A, 657(2), 229 (1993).

2. I. S. Metcalfe, Catal. Today, 9(1-2), 236 (1991).

3. X. Song and A. Sayari, Catal. Rev. Sci. Eng., 38(3), 329 (1996).

4. K. Tanabe and T. Yamaguchi, Catal. Today, 20(2), 185 (1994).

5. S. Zhou, G. Garnweitner, M. Niederberger and M. Antonietti, Langmuir, 23(18), 9178 (2007).

6. R. J. Ackermann, S. P. Garg, E. G. Rauh, High Temp. Sci., 11(3), 199 (1979).
7. J. P. Coughlin and E. G. King, J. Am. Chem. Soc., 72(5), 2262 (1950).

8. R. C. Garvie, J. Phys. Chem., 69(4), 1238 (1965).

9. M. W. Pitcher, S. V. Ushakov, A. Navrotsky, B. F. Woodfield, G. S. Li, J. Boerio-Goates and B. M. Tissue, J. Am. Ceram. Soc., 88(1), 160 (2005).

10. H. F. Holmes, E. L. Fuller Jr. and R. B. Gammage, J. Phys. Chem., 76(10), 1497 (1972).

11. I. Kasatkin, F. Girgsdies, T. Ressler, R. A. Caruso, J. H. Schattka, J. Urban and K. Weiss, J. Mater. Sci., 39(6), 2151 (2004).

12. M. Dechamps, B. Djuricic and S. Pickering, J. Am. Ceram. Soc., 78(11), 2873 (1995).

13. K. Matusui, H. Suzuki, M. Ohagi and H. Arashi, J. Am. Ceram. Soc., 78(1), 146 (1995).

14. W. Pyda, K. Haberko and M. M. Bucko, J. Am. Ceram. Soc., 74(10), 2622 (1991).

15. H. Nishizawa, N. Yamasaki, K. Matsuoka and H. Mitsushio, J. Am. Ceram. Soc., 65(7), 343 (1982).

16. G. Dell'Agli and G. Mascolo, J. Eur. Ceram. Soc., 20(2), 139 (2000).

17. E. Tani, M. Yoshimura and S. Somiya, J. Am. Ceram. Soc., 64(12), C-181 (1981).

18. E. Tani, M. Yoshimura and S. Somiya, J. Am. Ceram. Soc., 66(1), 11 (1983).

19. H. Kumazawa, T. Inoue and E. Sada, Chem. Eng. J., 55, 93 (1994).

20. C. E. Scott and J. S. Reed, Am. Ceram. Soc. Bull., 58, 587 (1979).

21. H. Toraya, M. Yoshimura and S. Somiya, J. Am. Ceram. Soc., 67(6), C-119 (1984).

22. A. Guinier, Theorie et Technique de la Radiocristallographie, $3^{\text {rd }}$ ed., p.482, Dunod Paris, France, (1964).

23. R. Vivekanandan and T. R. N. Kutty, Powder Technology, 57, 181 (1989).

24. R. Srinivasan, C. R. Hubbard, O. B. Cavin and B. H. Davis, Chem. Mater., 5, 27 (1993). 